\title{
One in Three Luxembourg Residents Report their Mental Health Declined during the COVID-19 Crisis
}

\author{
Kelsey J. O'Connor ${ }^{1}$ (1) $\cdot$ Chiara Peroni $^{1}$
}

Received: 17 July 2020 / Accepted: 22 October 2020/Published online: 18 November 2020

(C) Springer Nature Switzerland AG 2020

\begin{abstract}
COVID-19 has had unprecedented effects on people around the world, causing even the best performing communities to live in uncertainty for the future. How are people coping? We - the general public, the academic community, and policy makers - need answers. To that end we analyse novel data for Luxembourg, finding one third of residents report their mental health declined during lockdown and young adults (ages 18-44) fared the worst. The most important contributors observed are physical health, income, and employment characteristics, such as working from home, which people seemed to enjoy. To limit collateral damage on mental health, various tools are available, which we briefly discuss.
\end{abstract}

Keywords COVID-19 · Mental health $\cdot$ Public policy $\cdot$ Social distancing $\cdot$ Lockdown

The COVID-19 pandemic and fight against it has had significant collateral effects on mental health. Based on recently collected data by STATEC, ${ }^{1}$ the Luxembourg National Institute of Statistics and Economic Studies - one in three Luxembourg residents reported a decline in their mental health (santé morale). Such psychological effects were often ignored during the initial stages of the pandemic. Yet, as countries gain some control over the contagion, they have expanded their focus in hopes of addressing these issues. To that end, we examine plausible causes of mental distress during the period of lockdown in Luxembourg.

Authorities and the public are beginning to address the mental health consequences of the COVID-19 outbreak. The consequences derive from both the direct impacts of the virus and the lockdown measures, which impose strict social distancing and limits

${ }^{1}$ COVID-19 Social and Economic Impact Survey, a nationally representative survey conducted by STATEC in collaboration with TNS Ilres.

Kelsey J. O'Connor

Kelsey.OConnor@statec.etat.lu

1 STATEC Research (National Institute of Statistics and Economic Studies), Luxembourg, Luxembourg 
to time spent outdoors. This attention is necessary. Mental health is one of the most important components of well-being (Flèche and Layard 2017), and well-being is not only intrinsically important but positively affects traditional economic outcomes (eg., DiMaria et al. 2019; O'Connor 2020). Indeed the World Health Organization changed their recommendation from social distancing to physical distancing at the end of March 2020, in order to mitigate the impacts of lockdown measures on mental health. ${ }^{2}$ Social isolation is expected to affect the whole population and its effects on youth and the elderly in particular have caught public attention. ${ }^{3}$ What is more, deteriorating mental health could lead to a vicious cycle - fear, despair, depression, and isolation which lead to poor physical health, economic and social outcomes, which in turn reinforce negative mental health conditions.

What is causing this distress? People may fear infection for themselves and loved ones or feel a general sense of anxiety, concern, or uncertainty. They may have lost or fear losing their job. Perhaps they are tired of working from home, feel isolated or depressed.

\section{Sources of Distress in Luxembourg}

$6.4 \%$ of the respondents reported being furloughed due to COVID-19 under the scheme known as "partial unemployment" (chomage partiel); a further $2.7 \%$ are unemployed, and about one quarter $(24.7 \%)$ believe their job security will worsen in the future. Each group is likely to experience lower well-being, yet these figures suggest the employment consequences of COVID-19 have actually been less severe in Luxembourg than in other countries. ${ }^{4}$ For example, more than the 40 million people have filed for unemployment benefits from mid-March to the end of May in the United States. ${ }^{5}$ However, unemployment is still a concern. It is one of the most important factors contributing to people's feelings of well-being and mental health (Clark 2018). Even employed people are affected, fearing job loss (Luechinger et al. 2010), and becoming unemployed negatively affects well-being through more than the loss of income alone (Winkelmann and Winkelmann 1998). Through measures such as chomage partiel, Luxembourg attempted to save as many jobs as possible.

Declines in income are also a likely source of distress. Indeed, scholars have found that income losses have larger effects on people's well-being than equivalent income gains (De Neve et al. 2018; Kahneman and Tversky 1979). 16\% of the population

\footnotetext{
${ }^{2}$ Social interaction is important for mental health and possible while practicing responsible containment measures, for instance maintaining appropriate distances, avoiding crowded spaces (especially indoors), using face masks, and using communication technology.

${ }^{3}$ Three sources shed light on the mental health issues associated with COVID19: (1) from the World Health Organization http://www.euro.who.int/en/health-topics/health-emergencies/coronavirus-covid-19/novelcoronavirus-2019-ncov-technical-guidance-OLD/coronavirus-disease-covid-19-outbreak-technical-guidanceeurope-OLD/mental-health-and-covid-19; (2) from the Gallup survey organization: https://news.gallup.com/ poll/295505/coronavirus-worries-surge.aspx; and (3) from the OECD http:/www.oecd.org/coronavirus/ policy-responses/covid-19-protecting-people-and-societies-e5c9de1a/\#section-d1e426.

${ }^{4}$ The latest unemployment rate for Luxembourg is $6.9 \%$ (computed by STATEC in April), which is $1.5 \%$ higher than the previous year. However, this compares favourably to the EU average of the $7.4 \%$ (March 2020), and to other OECD countries (http://www.oecd.org/sdd/labour-stats/unemployment-ratesoecd-05-2020.pdf).

${ }^{5}$ Source: https://www.nytimes.com/2020/05/28/business/unemployment-stock-market-coronavirus.html
} 
experienced declines in income. The main reported causes of income loss were the loss of employment $(21 \%)$, the reduction of working hours $(24 \%)$, lower wages or business profits $(21 \%)$ and other $(35 \%)$. Nearly $60 \%$ of individuals reported a decrease in their expenses, too. However, we do not know by how much they decreased, and $16 \%$ of people incurred increased expenses.

Working conditions radically changed following the outbreak. At the time of the survey in April 2020, nearly 50\% of the workforce worked from home, while another $21 \%$ alternated between home and their employer's premises. How might working from home affect one's well-being? Some people may enjoy the flexibility, while others have difficulty meeting their responsibilities; some have added household duties or feel cut off from their social networks - clearly these represent just a few of the experiences one might have and they are not mutually exclusive. However, the majority of people $(55 \%)$ like working from home, while approximately $15 \%$ do not, and the remaining $30 \%$ are indifferent.

We do not have data on whether people feel socially isolated or lonely in this survey. However, this is an important dimension of mental health for which the United Kingdom has a dedicated ministry and the United States has declared an epidemic. In recent years, the share of people living alone in Luxembourg was $15 \%$ or lower, a little less than the EU average. ${ }^{6}$ The current survey indicates $17 \%$ of people live alone. This might have consequences on well-being, as studies show that cohabitation with a partner leads to a lasting improvement in feelings of well-being (Zimmermann and Easterlin 2006). However, living alone does not necessarily mean that someone feels lonely.

\section{Young People Were most Affected}

Figure 1 presents the declines in mental health across groups. Younger people fared worse than older. Of those aged 18-44, approximately $37 \%$ reported worsening mental health. This figure drops for each age group. Among the group 65 years and older, only $22 \%$ experienced worsening mental health. Compared to men, more women experienced worsening mental health. Across nationalities, the Portuguese fared the worst (40\% experienced declines), while those from other EU countries fared best. Across regions in Luxembourg, the largest declines occurred in the South and Luxembourg city (35 and $34 \%$ respectively). The best regional performer is the centre outside of Luxembourg city, with a decline of $28 \%$.

As Fig. 1 shows, the crisis has been experienced by different people in different ways. A natural question is, why. Perhaps Portuguese residents are on average younger, and that is why they fared worse, or there are more women living in the southern region of Luxembourg. We account for each factor simultaneously using regression analysis (ordered probit).

Figure 2 below shows the relations between declining mental health and factors such as demographic characteristics, region of residence, changes to health and income, employment status, feeling of job security, working from home, and a few unreported factors, such as education.

\footnotetext{
${ }^{6}$ Source: EUROSTAT: Distribution of population by household types - EU-SILC survey [TESOV190].
} 

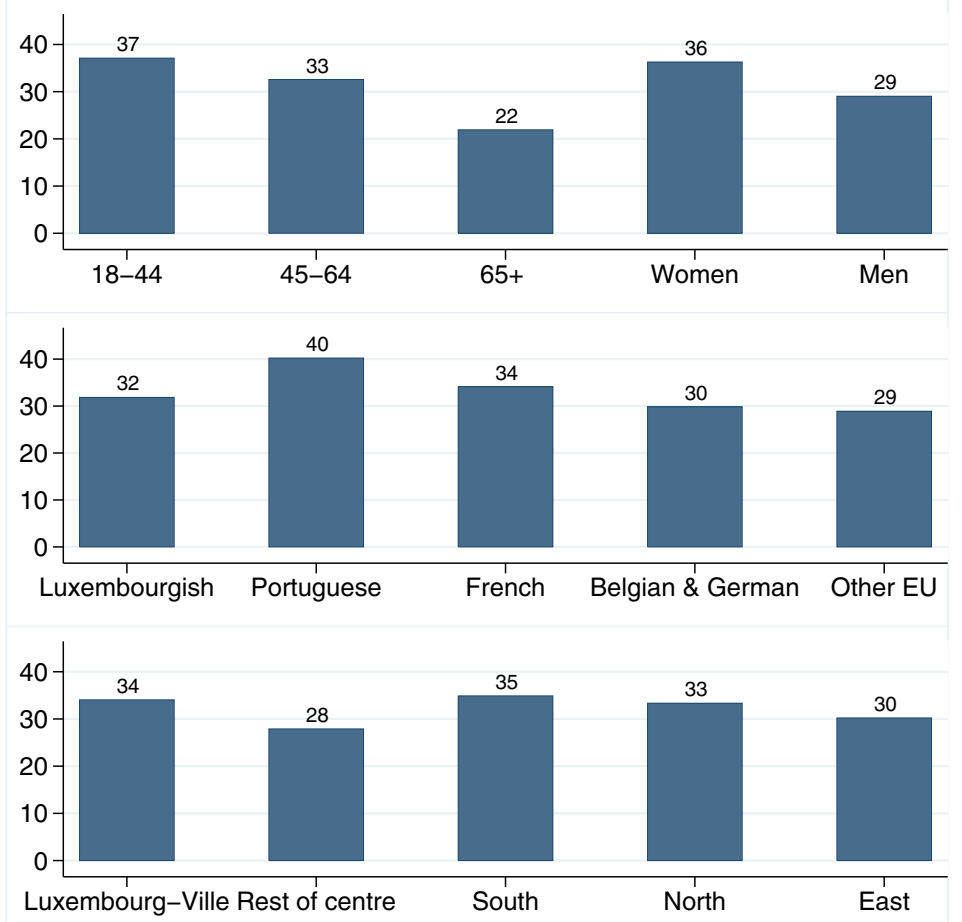

Fig. 1 Percent of the population that reported a decline in their mental health, by age, gender, nationality, and region. Source: author calculations using the STATEC ILRES survey, April 2020

The results indicate women are more likely to report a decline in mental health when simultaneously accounting for each of the other factors, however not statistically significantly. The $90 \%$ confidence interval for women includes zero. By age group, the middle age and older groups are also not statistically different from the comparison group of those 18-44 years old. For gender and age, although the means presented in Fig. 1 suggest there is a substantial difference between groups, the regression analysis indicates that the differences are in fact due to something else. The same is true of nationality and region. Put in other terms, although certain nationalities, regions, women, and younger people are more likely to have reported a decline in their mental health, these characteristics did not cause the decline in mental health. The same is true by level of education (not presented).

The most important factors associated with the decline in mental health are physical health, income, and employment characteristics (as presented in Fig. 2). After accounting for the other factors (e.g., age), someone that experienced a decline in their physical health is about $35 \%$ more likely to also experience a decline in their mental health. Similarly, if an individual's revenue decreased or expenses increased, they are more likely to report a decline, at about five and $9 \%$ respectively. Somewhat surprisingly, being unemployed is not statistically related to declining mental health, however, that may be because they were unemployed prior to the pandemic and did not experience a further decline during the crisis. Job security does have the expected relation. Those 


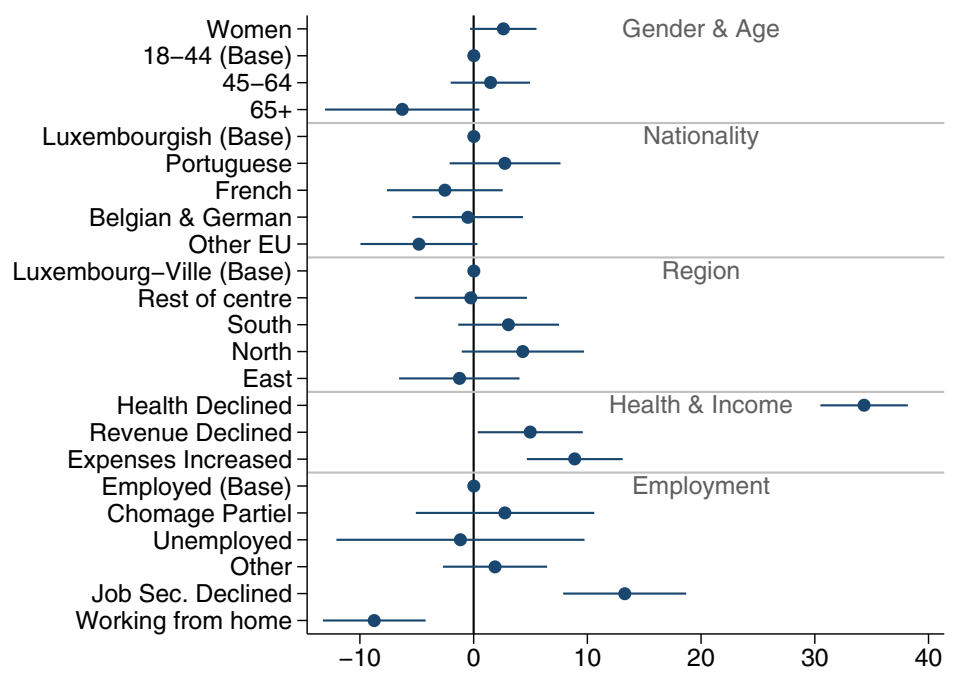

Fig. 2 Mental Health Decline. Change in probability (\%) of decline associated with different characteristics. Notes: Horizontal lines represent $90 \%$ confidence intervals. Base categories are references for which other categories are compared. For example, living in the various regions (e.g., North) is compared with living in Luxembourg-ville. The estimates are based on an ordered probit regression of mental health change for 2020 people on these characteristics as well as education and characteristics of the household: number of people living there, whether or not a child or elderly person lives there, whether the respondent lives in an apartment, house, or other and if it has external amenities (e.g. garden or terrace), and the number of people living there per room. Estimates are presented as marginal effects. Source: author calculations using the STATEC ILRES survey, April 2020

who felt their job security had deteriorated since the beginning of confinement were about $13 \%$ more likely to experience a decline in mental health. While in contrast, those working from home were about $9 \%$ less likely to report a decline in mental health.

\section{Discussion}

Other factors may also explain why people experienced declines in their mental health, as discussed above. It is difficult to measure the impacts of lockdown: staying at home, reduced contact with colleagues, friends, family, nature, and the uncertainty associated with the direction and implications of the pandemic.

We solely assess the short-term impacts of the pandemic. While declines in physical health, income, and job security are associated with declining mental health, people seem to enjoy working from home, and the government program chomage partiel is not statistically related to lower mental health. We believe the Luxembourg government did well to implement chomage partiel in order to save jobs in the short run. We know from previous research that there are long-term negative consequences of unemployment on mental health. However, new long run solutions are necessary. As an example set of targets, see the United Kingdom's Build Back Better campaign (https://www. buildbackbetteruk.org). 
To date, there are few studies that assess the psychological impacts of Covid-19 (Brodeur et al. 2020; Greyling et al. 2020; Hamermesh 2020). Recently, the preliminary results from another survey in Luxembourg were released, which also includes France, Germany, Italy, Spain and Sweden (Vögele et al. 2020). The United Kingdom's Office of National Statistics (ONS) has released some similar outcomes to those presented here (e.g., young adults fared worst), and the COVID-19 SocialStudy is regularly releasing new results on the psychological impacts of the pandemic. ${ }^{7}$

Social distancing, as it was called, places strain on already strained populations, however physical distancing successfully slows the spread of the virus (Flaxman et al. 2020; Hsiang et al. 2020; Kraemer et al. 2020; Lai et al. 2020; Pei et al. 2020). Echoing others, but it bears repeating, we need to keep at it; more research is necessary; targeted policies, for containment and the relaxation of containment, are necessary; and not least, physical distancing does not mean social distancing. Mental health concerns are not to be disregarded.

Acknowledgements The authors gratefully acknowledge the financial support of the Observatoire de la Compétitivité, Ministère de 1'Economie, DG Compétitivité, Luxembourg, and STATEC. This paper follows an earlier version released by the same title (Peroni and O'Connor, STATEC Regards No 8, 2020). The authors declare that they have no conflict of interest. Views and opinions expressed in this article are those of the authors and do not reflect those of STATEC, or funding partners.

\section{References}

Brodeur, A., Clark, A.E., Fleche, S., Powdthavee, N., (2020). Assessing the impact of the coronavirus lockdown on unhappiness, loneliness, and boredom using Google Trends, arXiv:2004.12129.

Clark, A. E. (2018). Four decades of the economics of happiness: Where next? Review of Income and Wealth, 64, 245-269. https://doi.org/10.1111/roiw.12369.

De Neve, J.-E., Ward, G., De Keulenaer, F., Van Landeghem, B., Kavetsos, G., \& Norton, M. I. (2018). The asymmetric experience of positive and negative economic growth: Global evidence using subjective wellbeing data. The Review of Economics and Statistics, 100, 362-375. https://doi.org/10.1162/REST_a 00697.

DiMaria, C. H., Peroni, C., \& Sarracino, F. (2019). Happiness Matters: Productivity Gains from Subjective Well-Being. Journal of Happiness Studies. https:/doi.org/10.1007/s10902-019-00074-1.

Flaxman, S., Mishra, S., Gandy, A., Unwin, H. J. T., Mellan, T. A., Coupland, H., Whittaker, C., Zhu, H., Berah, T., Eaton, J. W., Donnelly, C. A., Riley, S. M., Vollmer, M. A. C., Ferguson, N. M., \& Okell, L. C. (2020). Estimating the effects of non-pharmaceutical interventions on COVID-19 in Europe. Nature., 584, 257-261. https://doi.org/10.1038/s41586-020-2405-7.

Flèche, S., \& Layard, R. (2017). Do more of those in misery suffer from poverty, unemployment or mental illness? Kyklos, 70, 27-41. https://doi.org/10.1111/kykl.12129.

Greyling, T., Rossouw, S., Adhikari, T., 2020. Happiness-lost: Did governments make the right decisions to combat Covid-19? (no. 556), GLO discussion paper.

Hamermesh, D.S., (2020). Lock-downs, loneliness and life satisfaction (no. 27018), NBER Working Paper Series.

Hsiang, S., Allen, D., Annan-Phan, S., Bell, K., Bolliger, I., Chong, T., Druckenmiller, H., Huang, L. Y., Hultgren, A., Krasovich, E., Lau, P., Lee, J., Rolf, E., Tseng, J., \& Wu, T. (2020). The effect of large-scale anti-contagion policies on the COVID-19 pandemic. Nature., 584, 262-267. https://doi.org/10.1038/ s41586-020-2404-8.

\footnotetext{
${ }^{7}$ ONS: https://www.ons.gov.uk/peoplepopulationandcommunity/birthsdeathsandmarriages/ageing/articles/ coronavirusandthesocialimpactsonyoungpeopleingreatbritain/3aprilto10may2020; COVID-19 SocialStudy: covidsocialstudy.org
} 
Kahneman, D., \& Tversky, A. (1979). Prospect theory : An analysis of decision under risk. Econometrica, 47, 263-292.

Kraemer, M. U. G., Yang, C.-H., Gutierrez, B., Wu, C.-H., Klein, B., Pigott, D. M., du Plessis, L., Faria, N. R., Li, R., Hanage, W. P., Brownstein, J. S., Layan, M., Vespignani, A., Tian, H., Dye, C., Pybus, O. G., $\&$ Scarpino, S. V. (2020). The effect of human mobility and control measures on the COVID-19 epidemic in China. Science (80-. ), 368, 493-497. https://doi.org/10.1126/science.abb4218.

Lai, S., Ruktanonchai, N. W., Zhou, L., Prosper, O., Luo, W., Floyd, J. R., Wesolowski, A., Santillana, M., Zhang, C., Du, X., Yu, H., \& Tatem, A. J. (2020). Effect of non-pharmaceutical interventions to contain COVID-19 in China. Nature., 585, 410-413. https://doi.org/10.1038/s41586-020-2293-x.

Luechinger, S., Meier, S., \& Stutzer, A. (2010). Why does unemployment hurt the employed?: Evidence from the life satisfaction gap between the public and the private sector. The Journal of Human Resources, 45, 998-1045. https://doi.org/10.3368/jhr.45.4.998.

O'Connor, K. J. (2020). Life satisfaction and noncognitive skills: Effects on the likelihood of unemployment. Kyklos, 73, 568-604. https://doi.org/10.1111/kykl.12226.

Pei, S., Kandula, S., Shaman, J., (2020). Differential effects of intervention timing on COVID-19 spread in the United States. medRxiv 2020.05.15.20103655. https://doi.org/10.1101/2020.05.15.20103655.

Winkelmann, L., \& Winkelmann, R. (1998). Why are the unemployed so unhappy? Evidence from panel data. Economica, 65, 1-15. https://doi.org/10.1111/1468-0335.00111.

Zimmermann, A. C., \& Easterlin, R. A. (2006). Happily ever after? Cohabitation, marriage, divorce, and happiness in Germany. Population and Development Review, 32, 511-528.

Vögele, C., Lutz, A., Yin, R., Ambrosio, C.D., (2020). How do different confinement measures affect people in Luxembourg, France, Germany, Italy, Spain and Sweden?, COME-HERE: First Report.

Publisher's Note Springer Nature remains neutral with regard to jurisdictional claims in published maps and institutional affiliations. 